Trauma Surgery \& Acute Care Open

\title{
Hypercoagulability in pregnant trauma patients
}

\author{
Lisa J Toelle, Gabrielle E Hatton, Jerrie S Refuerzo, Charles E Wade, Bryan A Cotton, \\ Lillian S Kao
}

\begin{abstract}
- Additional supplemental material is published online only. To view, please visit the journal online (http://dx.doi. org/10.1136/tsaco-2021-
\end{abstract}

000714).

Surgery, McGovern Medical School at University of Texas Health Science Center at Houston, Houston, Texas, USA

Correspondence to Dr Lisa J Toelle; lisa.j.toelle@ uth.tmc.edu (c) Author(s) (or their employer(s)) 2021. Re-use permitted under CC BY-NC. No commercial re-use. See rights and permissions. Published by BMJ.

To cite: Toelle LJ, Hatton GE, Refuerzo JS, et al. Trauma Surg Acute Care Open 2021:6:e000714.

\begin{abstract}
Circulating hormones affect coagulopathy in pregnancy and after trauma. The hemostatic profile of pregnant women after injury has not been characterized. We hypothesized that injured pregnant females would present with an initial thrombelastography (TEG) reflecting a more hypercoagulable profile and a higher incidence of venous thromboembolic events (VTE) when compared with non-pregnant females and males.

Methods Cohort study of adult trauma patients with TEG measured on arrival was performed from 2009 to 2018 with data extracted from medical records. Nearest-neighbor matching was used to match each pregnant patient by age, Injury Severity Score, prehospital transfusion, and arrival Glasgow Coma Scale with nonpregnant females and males, each in a maximum 1:4 ratio. Hypercoagulable profiles were defined as alpha $(\alpha)$ angle $\geq 76^{\circ}$ and maximum amplitude $(M A) \geq 65 \mathrm{~mm}$. Lysis at 30 minutes after MA (LY-30) was considered high if $\geq 3.0 \%$ and low if $\leq 0.8 \%$. Univariate and multivariable analyses were performed.

Results Seventy-six pregnant trauma patients were matched to 301 non-pregnant females and 301 males. Demographics were similar between groups, except pregnant females more frequently suffered blunt trauma. Pregnant females presented with a higher $\alpha$ angle, high MA and lower LY-30 than both control groups. Pregnant females met hypercoagulable criteria and had a low LY-30 more frequently than non-pregnant females and males. No pregnant patient versus $2 \%$ in each control group developed VTE. Transfusion requirements in the first 24 hours after admission and mortality were similar between groups. After adjustment, low MA and high LY-30 were associated with increased odds of mortality, regardless of sex or pregnancy. Hypocoagulable $\alpha$ angle was associated with pregnancy complications.

Conclusion Injured pregnant females frequently presented with a profile that would be considered hypercoagulable under normal reference ranges. However, given the absence of VTE events, this profile may be non-pathologic.

Level of evidence IV.
\end{abstract}

\section{INTRODUCTION}

Sexual dimorphisms exist in response to major traumatic injury, shock and sepsis. Female sex is protective after severe trauma, resulting in decreased incidence of organ failure, reduced transfusion requirements, and lower mortality rate when compared with similarly injured males. ${ }^{1-6}$ Because the survival advantage is more apparent in premenopausal females, sex hormones may play an important role in this observed effect. ${ }^{7-9}$
Sex-related differences in thrombelastography (TEG) clotting profiles were noted over 20 years ago in normal subjects. Females had a more hypercoagulable profile compared with males, and when pregnant there is a more pronounced hypercoagulable profile. ${ }^{10-13}$ Similarly, trauma patients have a hypercoagulable TEG profile on hospital admission compared with normal subjects, even with minor injuries. ${ }^{14}$. This hypercoagulable profile persists during the first 24 hours after injury, with females being more hypercoagulable than men..$^{15-17}$ Sex differences in coagulation assessed by TEG are predominately evident in the alpha $(\alpha)$ angle, maximum amplitude (MA) values, and lysis 30 minutes after MA (LY-30) indicative of a faster rate of clot formation and a stronger clot, and greater clot stability. Hypercoagulability on arrival TEG, assessed by an increased $\alpha$ angle and MA, is associated with increased rates of thromboembolic events in trauma patients. ${ }^{18-21}$ This association was identified in study populations primarily consisting of males, about $75 \%$, and did not include pregnant females. Pregnancy is associated with an increased risk of thromboembolic events, raising the concern that hypercoagulability in pregnancy may be associated with increased thromboembolic events after trauma. ${ }^{22}$

The objective of this study was to evaluate differences in coagulation profiles as well as examine incidence of venous thromboembolic events (VTE) in pregnant females, non-pregnant females and males after traumatic injury. We hypothesized that injured pregnant females would present with an initial TEG reflecting an increased hypercoagulable profile compared with males and non-pregnant females, and that pregnant females would have higher incident of VTE when compared with non-pregnant females and males. Additionally, we hypothesized that a hypocoagulable profile would be associated with a higher rate of pregnancy complications.

\section{METHODS}

A retrospective analysis of prospectively collected data was conducted at the Red Duke Trauma Institute at Memorial Hermann Hospital-Texas Medical Center, a high-volume, level 1 trauma center in Houston, Texas, USA. A waiver of individual informed consent was obtained due to the retrospective nature of the study and the minimal risk to the individual participants. Adult $(\geq 16$ years) trauma patients presenting between 2009 and 2018 were included. Patients without a rapid TEG (rTEG) measured on arrival were excluded. Patients requiring highest level trauma activation had an rTEG measured on arrival as part of usual 


\begin{tabular}{lll}
\hline Table 1 & Rapid TEG interpretation & \\
\hline r-TEG value & Definition & Interpretation \\
\hline ACT $(\mathrm{s})$ & Time from start of assay to initiation of clot & Prolonged with factor deficiency or severe hemodilution \\
\hline Reaction time $(\mathrm{min})$ & Time between beginning of assay and initial clot formation & Prolonged with factor deficiency or severe hemodilution \\
\hline Kinetic time $(\mathrm{min})$ & Time needed to reach $20 \mathrm{~mm}$ clot strength & Increased with hypofibrinogenemia or platelet dysfunction \\
\hline$\alpha$ angle $\left(^{\circ}\right)$ & Rate or acceleration of clot formation & Decreased with hypofibrinogenemia or platelet dysfunction \\
\hline Maximum amplitude $(\mathrm{mm})$ & Contribution of platelet function and platelet-fibrin interactions & Decreased with platelet dysfunction and hypofibrinogenemia \\
\hline $\mathrm{LY}-30(\%)$ & Amplitude reduction 30 min after achieving MA (degree of fibrinolysis) & Increased with accelerated fibrinolysis \\
\hline
\end{tabular}

ACT, activated clotting time; LY-30, lysis 30 min after MA; MA, maximum amplitude; r-TEG, rapid TEG; TEG, thrombelastography.

clinical laboratory evaluation. Patients who obtained an rTEG measurement on arrival for other indications were also included in this study. Highest level trauma activation was triggered by any of the following: Glasgow Coma Scale (GCS) score $\leq 10$; heart rate $>120$ beats per minute; systolic blood pressure (SBP) $\leq 90 \mathrm{~mm} \mathrm{Hg}$; respiratory rate $<10$ or $>29$ per minute; intubation; penetrating injury to torso, groin, head or neck; amputation proximal to ankle or wrist; paraplegia or quadriplegia; uncontrolled external hemorrhage; fracture to pelvis or two or more long bone fractures; or receiving blood en route.

Demographic characteristics, comorbid conditions, injury details, laboratory results, and outcomes were obtained from the institution's professionally maintained trauma registry. Outcomes included transfusions required, deep vein thrombosis (DVT), pulmonary embolism (PE), in-hospital mortality, length of stay, and intensive care unit length of stay. Both DVTs and
PEs were recorded only if they were clinically diagnosed as the study institution did not use routine surveillance duplex studies. Pregnant patients were identified by a pregnancy comorbidity diagnosis and confirmed via chart review. Pregnancy-specific demographics and outcomes were obtained by chart review and included estimated gestational age (EGA), twin gestation status, peri-injury delivery, emergent cesarean section, preterm delivery, fetal demise, and maternal death. Peri-injury delivery was defined as delivery within 48 hours from hospital arrival. Emergent cesarean section was defined as cesarean delivery on the day of hospital presentation. Preterm delivery was defined as delivery prior to 38 weeks' EGA.

Arrival rTEG values were compared between groups. All rTEG specimens were run on a Thrombelastograph 5000 (Haemoscope, Niles, Illinois). Specimens were collected in citrated tubes, transported to the emergency department stat

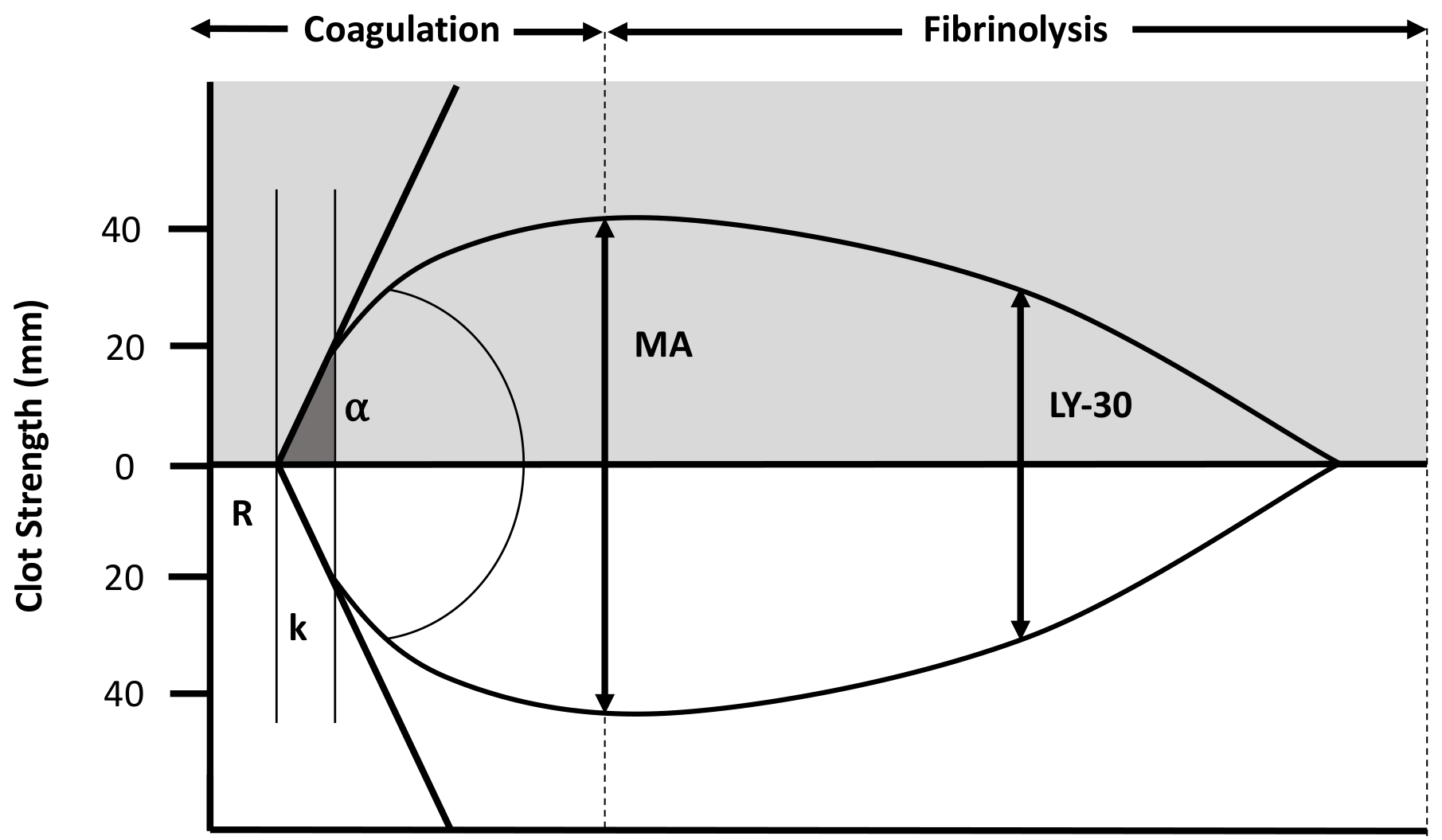

Time (minutes)

Figure 1 Thromboelastogram. Illustration of thrombelastography (TEG) tracing and the parameters measured through clot formation and fibrinolysis. The R-value expresses the time between the start of the assay and beginning of clot formation. The k-time is the time needed to reach $20 \mathrm{~mm}$ clot strength. The $\alpha$ angle is the slope of the tracing that represents rate of clot formation. The maximum amplitude (MA) is the greatest amplitude of the tracing and represents the strength of the fibrin clot. LY-30 is the percent amplitude reduction at 30 minutes after MA. 


\begin{tabular}{|c|c|c|c|c|c|}
\hline Demographic & $\begin{array}{l}\text { All patients } \\
(n=678)\end{array}$ & $\begin{array}{l}\text { Pregnant } \\
(n=76)\end{array}$ & $\begin{array}{l}\text { Non-pregnant } \\
(\mathrm{n}=301)\end{array}$ & $\begin{array}{l}\text { Male } \\
(n=301)\end{array}$ & P value* \\
\hline Age (years) & $24(20-30)$ & $24(20-30)$ & $25(20-31)$ & $24(20-30)$ & 0.62 \\
\hline Injury Severity Score & $10(5-21)$ & $12(5-21)$ & $12(6-21)$ & $10(5-21)$ & 0.83 \\
\hline Head AIS & $0(0-2)$ & $0(0-3)$ & $0(0-2)$ & $0(0-2)$ & 0.79 \\
\hline Face AIS & $0(0-0)$ & $0(0-0)$ & $0(0-0)$ & $0(0-0)$ & 0.77 \\
\hline Chest AIS & $0(0-3)$ & $0(0-3)$ & $0(0-3)$ & $0(0-3)$ & 0.66 \\
\hline Abdomen AIS & $0(0-2)$ & $0(0-2)$ & $0(0-2)$ & $0(0-2)$ & 0.48 \\
\hline Extremity AIS & $1(0-1)$ & $1(0-1)$ & $1(0-1)$ & $1(0-1)$ & 0.58 \\
\hline External AIS & $0(0-3)$ & $2(0-2)$ & $1(0-3)$ & $0(0-3)$ & 0.45 \\
\hline Blunt mechanism & $409(60 \%)$ & 67 (88\%) & $192(64 \%)$ & $150(50 \%)$ & $<0.001$ \\
\hline Transferred & $156(23 \%)$ & $18(24 \%)$ & $63(20 \%)$ & $75(25 \%)$ & 0.50 \\
\hline Prehospital transfusion & $67(10 \%)$ & $8(11 \%)$ & $29(10 \%)$ & $30(10 \%)$ & 0.82 \\
\hline ED SBP $(\mathrm{mm} \mathrm{Hg})$ & $122(110-138)$ & 118 (104-133) & $119(104-132)$ & $130(114-142)$ & $<0.001$ \\
\hline ED HR (bpm) & $100(84-118)$ & $104(86-118)$ & $104(88-120)$ & $95(81-115)$ & 0.002 \\
\hline ED GCS & $15(14-15)$ & $15(14-15)$ & $15(14-15)$ & $15(14-15)$ & 0.54 \\
\hline Hemoglobin (g/dL) & $13(11.7-14.3)$ & $11.7(10.6-12.2)$ & $12.4(11.2-13.4)$ & $14.1(13.2-15.0)$ & $<0.001$ \\
\hline Platelets (×109/L) & $248(206-297)$ & $230(191-267)$ & $263(216-317)$ & 243 (199-287) & $<0.001$ \\
\hline Base excess & $-2(-5$ to 0$)$ & $-3(-5$ to -2$)$ & $-3(-6$ to -1$)$ & $-2(-4$ to 0$)$ & $<0.001$ \\
\hline
\end{tabular}

Continuous data presented as median (IQR).

${ }^{*}$ Results of Kruskal-Wallis test.

AIS, Abbreviated Injury Scale; ED, emergency department; GCS, Glasgow Coma Scale; HR, heart rate; SBP, systolic blood pressure.

laboratory along with other trauma blood specimens. There, the citrate was immediately reversed with the addition of calcium chloride according to the recommendations of the manufacturer within the rTEG package insert. After this, standard rTEG was performed using tissue factor and kaolin as activators. The rTEG, similar to standard TEG, generates several values that describe the clotting cascade. The first value is the activated clotting time (ACT), the time in seconds between initiation of the test and the initial fibrin formation. Increases in ACT would indicate a factor deficiency or severe hemodilution. Similar to the ACT, the r-value (also known as the reaction time) expresses the time between the start of the assay and the beginning of clot formation. The kinetic $(\mathrm{k})$ time is the time needed to reach 20 $\mathrm{mm}$ clot strength; this is generally increased in states of hypofibrinogenemia. The $\alpha$ angle is the slope of the tracing that represents the rate of clot formation. The $\alpha$ angle is decreased with hypofibrinogenemia or platelet dysfunction. The MA is the greatest amplitude of the tracing and reflects platelet contribution to clot strength. Low MA values correspond with states of platelet dysfunction or hypofibrinogenemia. LY-30 is the percent amplitude reduction at 30 minutes after MA is reached and, when elevated, reflects a state of hyperfibrinolysis. A coagulation index (CI) was calculated as follows: $\mathrm{CI}=-0.2454$ *r $\mathrm{r}$ value $+0.0184 * \mathrm{MA}-0.241 * \alpha$ angle -5.0220 . Normal CI values usually fall between -3.0 and +3.0. A hypercoagulable state is consistent with $\mathrm{CI}>3.0$ and a hypocoagulable state is consistent with $<-3.0 .{ }^{1123}$

TEG derangement categories were predefined and compared between groups based on previous studies. For $\alpha$ angle, hypocoagulable was defined as $\leq 60^{\circ}$, hypercoagulable if $\geq 76^{\circ}$, and normal for all other values. ${ }^{24}$ Hypercoagulable was assigned if $\mathrm{MA} \geq 65$, hypocoagulable if $\mathrm{MA} \leq 55$, and normal for all others. ${ }^{1925}$ Finally, high LY-30 was assigned if $\geq 3 \%$, low LY-30 if $\leq 0.8 \%$, and normal for all others. ${ }^{26}{ }^{27}$ Basic rTEG interpretation was conducted according to manufacturer references (table 1, figure 1).

\section{Statistical analysis}

Nearest-neighbor matching was used to match each pregnant patient by age, Injury Severity Score (ISS), prehospital transfusion, and arrival GCS with males and non-pregnant females, each in a maximum 1:4 ratio to generate three unique groups. Demographics and outcomes with continuous variables were presented as medians and IQRs. $\chi^{2}$, Wilcoxon rank-sum, and Kruskal-Wallis tests were used to compare categorical and continuous demographic data and outcomes. Univariate analyses comparing outcomes between the three groups (pregnant female, non-pregnant female, and male) or by development of VTE were performed. The cohort of pregnant females was further split by an EGA of 23 weeks to better elucidate risk of complications at different stages of pregnancy and by coagulation profile according to $\alpha$ angle, MA, and LY-30 categories. A sensitivity analysis restricting the population to blunt trauma only was conducted due to a significantly higher proportion of pregnant patients suffering blunt trauma than males. Finally, subgroup analyses were performed restricted to patients who received prehospital blood. Due to small sample size, multivariable analyses in this population were not attempted.

Multivariable regression models with binomial distribution were used to assess the relationship between mortality, sex, pregnancy status, and abnormal TEG parameters. Covariates were selected a priori and included age, ISS, prehospital transfusion, arrival SBP, and arrival GCS. The model was assessed for interactions between covariates. All associations were reported as ORs with 95\% CIs. Stata V.15 was used for all analyses (StataCorp, College Station, Texas). The calipmatch plug-in for Stata V.15 was used for matching.

\section{RESULTS}

Seventy-six pregnant trauma patients were matched to 301 males and 301 non-pregnant females. No data were missing. The median age was 24 years (IQR 20-30) and median ISS was 10 (IQR 5-21) (table 2). Most patients were injured by blunt 
Open access

Table 3 Rapid TEG results on arrival

\begin{tabular}{|c|c|c|c|c|c|}
\hline TEG parameter & $\begin{array}{l}\text { All patients } \\
(n=678)\end{array}$ & $\begin{array}{l}\text { Pregnant } \\
(n=76)\end{array}$ & $\begin{array}{l}\text { Non-pregnant } \\
(\mathrm{n}=301)\end{array}$ & $\begin{array}{l}\text { Male } \\
(n=301)\end{array}$ & $P$ value* \\
\hline ACT (s) & $113(105-121)$ & $113(105-121)$ & $105(105-113)$ & $113(105-121)$ & $<0.001$ \\
\hline Split point time (min) & $0.5(0.4-0.6)$ & $0.5(0.4-0.6)$ & $0.5(0.4-0.6)$ & $0.6(0.5-0.6)$ & 0.003 \\
\hline Reaction time (min) & $0.7(0.6-0.8)$ & $0.7(0.6-0.8)$ & $0.6(0.5-0.7)$ & $0.7(0.6-0.8)$ & $<0.001$ \\
\hline Kinetic time (min) & $1.2(1.0-1.7)$ & $1.1(0.9-1.2)$ & $1.2(0.9-1.4)$ & $1.5(1.2-1.8)$ & $<0.001$ \\
\hline$\alpha$ angle $\left(^{\circ}\right)$ & $75(71-77)$ & $77(74-79)$ & $76(73-78)$ & $72(68-75)$ & $<0.001$ \\
\hline Maximum amplitude (mm) & $65(60-69)$ & $69(65-72)$ & $67(62-70)$ & $63(57-66)$ & $<0.001$ \\
\hline G-value (d/sc) & $9.1(7.4-11.1)$ & $11(9.3-13)$ & $9.9(8.0-11.7)$ & $8.1(6.7-9.5)$ & 0.001 \\
\hline LY-30 (\%) & $1.5(0.4-3.2)$ & $0.8(0-2.7)$ & $1.7(0.5-3.4)$ & $1.5(0.4-3.2)$ & 0.02 \\
\hline Coagulation index & $3.7(3.0-4.4)$ & $4.4(3.8-4.8)$ & $4.1(3.3-4.6)$ & $3.4(2.7-3.9)$ & $<0.001$ \\
\hline \multicolumn{6}{|l|}{ TEG category } \\
\hline Hypocoagulable (MA $\leq 55$ ) & $61(9 \%)$ & $5(7 \%)$ & $21(7 \%)$ & $35(12 \%)$ & 0.10 \\
\hline Hypocoagulable ( $\alpha$ angle $\leq 60^{\circ}$ ) & $24(4 \%)$ & $3(4 \%)$ & $6(2 \%)$ & $15(5 \%)$ & 0.14 \\
\hline High LY-30 (lysis $\geq 3.0 \%$ ) & $213(31 \%)$ & $17(22 \%)$ & $103(34 \%)$ & $93(31 \%)$ & 0.10 \\
\hline Normocoagulable (MA 56-64) & $275(41 \%)$ & $11(14 \%)$ & $102(34 \%)$ & $162(54 \%)$ & $<0.001$ \\
\hline Normocoagulable ( $\alpha$ angle $61^{\circ}-75^{\circ}$ ) & $379(56 \%)$ & $24(32 \%)$ & $137(46 \%)$ & $218(72 \%)$ & $<0.001$ \\
\hline Physiologic lysis & $222(33 \%)$ & $19(25 \%)$ & $101(34 \%)$ & $102(34 \%)$ & 0.20 \\
\hline Hypercoagulable ( $\alpha$ angle $\geq 76^{\circ}$ ) & $275(41 \%)$ & $49(64 \%)$ & $158(52 \%)$ & $68(23 \%)$ & $<0.001$ \\
\hline Hypercoagulable (MA $\geq 65$ ) & $342(50 \%)$ & $60(79 \%)$ & $178(59 \%)$ & $104(34 \%)$ & $<0.001$ \\
\hline Low LY-30 (lysis $\leq 0.8 \%$ ) & $243(36 \%)$ & $40(53 \%)$ & $97(32 \%)$ & $106(35 \%)$ & 0.005 \\
\hline
\end{tabular}

Continuous data presented as median (IQR).

${ }^{*}$ Results of Kruskal-Wallis test.

ACT, activated clotting time; LY-30, lysis 30 min after MA; MA, maximum amplitude; TEG, thrombelastography.

mechanism and were transported directly from the scene. Ten percent of patients received a prehospital transfusion. Patients most frequently arrived with normal SBP and GCS with medians of $122 \mathrm{~mm} \mathrm{Hg}$ and 15, respectively. Matched demographics, which included age, ISS, transfer status, prehospital transfusion, and arrival GCS, were similar between groups. Pregnant females were most frequently injured by blunt mechanism, followed by non-pregnant females, and finally, males. Pregnant females also had the lowest arrival SBP compared with non-pregnant females and males. Additionally, pregnant females had the lowest arrival hemoglobin and platelets.

Pregnant females presented with a higher median MA, higher $\alpha$ angle, higher CI, lower LY-30, and lower k-time than both control groups (table 3). Pregnant females were most frequently hypercoagulable by both MA and $\alpha$ angle criteria. Males were most frequently normocoagulable than both pregnant and nonpregnant females. Hypocoagulability by both MA and $\alpha$ angle criteria was uncommon across groups. Additionally, pregnant females had low LY-30 more frequently than non-pregnant females and males (table 3).

Clinically apparent PE and DVT were both infrequent in the overall cohort (table 4). No pregnant patient suffered either PE or DVT whereas 2\% of non-pregnant females suffered DVT and $1 \%$ suffered PE. Males suffered DVTs and PEs at rates of $1 \%$ and $0.3 \%$, respectively. Transfusion requirements, lengths of stay and mortality were similar between groups. Patients who suffered PE or DVT had a higher ISS, chest Abbreviated Injury Scale (AIS), abdomen AIS, and extremity AIS than those who did not suffer PE or DVT $(p<0.05)$.

The median EGA on hospital arrival was 22 weeks (IQR 14-31) among pregnant patients (table 5). One patient had a twin gestation. Twenty-eight patients (37\%) suffered a documented pregnancy-related complication, which was most frequently peri-injury delivery; the majority of these deliveries were preterm. Seven patients (9\%) underwent emergent

\begin{tabular}{|c|c|c|c|c|c|}
\hline Outcome & $\begin{array}{l}\text { All patients } \\
(n=678)\end{array}$ & $\begin{array}{l}\text { Pregnant } \\
(n=76)\end{array}$ & $\begin{array}{l}\text { Non-pregnant } \\
(n=301)\end{array}$ & $\begin{array}{l}\text { Male } \\
(n=301)\end{array}$ & $\begin{array}{l}P \\
\text { value* }\end{array}$ \\
\hline Transfusion $\geq 1 \mathrm{u}$ in $24 \mathrm{~h}$ & $114(17 \%)$ & $12(16 \%)$ & $52(17 \%)$ & $50(17 \%)$ & 0.95 \\
\hline Tranexamic acid & $13(2 \%)$ & 0 & $6(2 \%)$ & $7(2 \%)$ & 0.41 \\
\hline Deep vein thrombosis & $6(1 \%)$ & 0 & $3(1 \%)$ & $3(1 \%)$ & 0.68 \\
\hline Pulmonary embolism & $8(1 \%)$ & 0 & $7(2 \%)$ & $1(0.3 \%)$ & 0.05 \\
\hline Length of stay (days) & $5(2-11)$ & $4(2-8)$ & $5(2-12)$ & $4(2-12)$ & 0.19 \\
\hline Intensive care unit days & $0(0-2)$ & $0(0-1)$ & $0(0-2)$ & $0(0-2)$ & 0.21 \\
\hline Ventilator days & $0(0-1)$ & $0(0-0)$ & $0(0-1)$ & $0(0-1)$ & 0.43 \\
\hline Mortality & $29(4 \%)$ & $4(5 \%)$ & $16(5 \%)$ & $9(3 \%)$ & 0.33 \\
\hline
\end{tabular}

Continuous data presented as median (IQR).

${ }^{*}$ Results of Kruskal-Wallis test. 


\begin{tabular}{|c|c|c|c|c|}
\hline $\begin{array}{l}\text { Pregnancy } \\
\text { demographics and } \\
\text { obstetric outcomes }\end{array}$ & $\begin{array}{l}\text { All patients } \\
(\mathrm{n}=76)\end{array}$ & $\begin{array}{l}<23 \text { weeks' } \\
E G A \\
(n=40)\end{array}$ & $\begin{array}{l}\geq 23 \text { weeks' } \\
E G A \\
(n=36)\end{array}$ & P value* \\
\hline $\begin{array}{l}\text { Estimated gestational age } \\
\text { at arrival (weeks) }\end{array}$ & $22(14-31)$ & $15(8-19)$ & $31(26-34)$ & $<0.001$ \\
\hline Twin gestation & $1(1 \%)$ & $1(3 \%)$ & 0 & 0.34 \\
\hline Peri-injury delivery & $27(36 \%)$ & $11(27 \%)$ & $16(44 \%)$ & 0.12 \\
\hline Emergent cesarean section & $7(9 \%)$ & 0 & 7 (19\%) & 0.003 \\
\hline $\begin{array}{l}\text { Preterm delivery (<38 } \\
\text { weeks) }\end{array}$ & $24(32 \%)$ & $10(25 \%)$ & $18(39 \%)$ & 0.19 \\
\hline Fetal demise & $12(16 \%)$ & $9(23 \%)$ & $3(8 \%)$ & 0.09 \\
\hline Maternal death & $4(5 \%)$ & $1(3 \%)$ & $3(8 \%)$ & 0.26 \\
\hline
\end{tabular}

Continuous data presented as median (IQR).

${ }^{*}$ Results of Wilcoxon rank-sum test.

$E G A$, estimated gestational age.

cesarean section. Finally, 12 patients (16\%) experienced fetal demise. Forty patients (53\%) had an EGA prior to 23 weeks. Peri-injury delivery was more frequent after 23 weeks' EGA and all emergent cesarean sections were performed after 23 weeks' EGA. There were fewer cases of fetal demise after 23 weeks' EGA. Pregnant females who suffered an obstetric complication had a lower $\alpha$ angle than those who did not suffer a complication ( $\alpha$ angle $75.5^{\circ}$ (IQR 70.5-78) vs. $77^{\circ}$ (IQR 75-79), $\mathrm{p}=0.02$ ). All pregnant patients with a hypocoagulable $\alpha$ angle suffered a pregnancy complication (table 6). Pregnant patients with a hypocoagulable $\alpha$ angle or MA were more severely injured and arrived with higher heart rate and lower base excess. They were more frequently transfused and suffered higher rates of obstetric complications and higher mortality (online supplemental tables $1-3)$.

After adjustment (age, ISS, GCS, and sex or pregnancy group), high LY-30 was associated with increased odds of mortality with an OR 5.95 (95\% CI 1.12 to $31.68, \mathrm{p}=0.04)$. Additionally, hypercoagulability based on MA was associated with decreased odds of mortality with an OR 0.20 (95\% CI 0.05 to 0.72 , $\mathrm{p}=0.01)$. Finally, hypocoagulability based on $\alpha$ angle was associated with increased odds of mortality with an OR 6.26 (95\% CI 1.57 to 25.00 ). Findings were similar on sensitivity analysis of blunt trauma patients only.

Patients who received prehospital blood were severely injured with a median ISS of 22 (IQR 17-29) and arrived with a median base excess of -5 (IQR -10 to -3 ). Due to small sample size,

\begin{tabular}{|c|c|c|c|}
\hline $\begin{array}{l}\text { Pregnancy demographics and } \\
\text { obstetric outcomes }\end{array}$ & $\begin{array}{l}\text { No pregnancy } \\
\text { complication } \\
(n=48)\end{array}$ & $\begin{array}{l}\text { Pregnancy } \\
\text { complication } \\
\text { ( } n=28)\end{array}$ & $\begin{array}{l}P \\
\text { value }\end{array}$ \\
\hline Hypocoagulable (MA $\leq 55)$ & $1(2 \%)$ & $3(11 \%)$ & 0.10 \\
\hline Hypocoagulable ( $\alpha$ angle $\leq 60^{\circ}$ ) & 0 & $3(11 \%)$ & 0.02 \\
\hline High LY-30 (lysis $\geq 3.0 \%$ ) & $11(23 \%)$ & $6(21 \%)$ & 0.88 \\
\hline Normocoagulable (MA 56-64) & $22(46 \%)$ & $15(54 \%)$ & 0.51 \\
\hline $\begin{array}{l}\text { Normocoagulable ( } \alpha \text { angle } \\
61^{\circ}-75^{\circ} \text { ) }\end{array}$ & $13(27 \%)$ & $11(39 \%)$ & 0.27 \\
\hline Physiologic LY-30 & $13(27 \%)$ & $6(21 \%)$ & 0.58 \\
\hline Hypercoagulable ( $\alpha$ angle $\geq 76^{\circ}$ ) & $35(73 \%)$ & $14(50 \%)$ & 0.04 \\
\hline Hypercoagulable (MA $\geq 65$ ) & $25(36 \%$ & $10(52 \%)$ & 0.16 \\
\hline Low LY-30 (lysis $\leq 0.8 \%$ ) & $24(50 \%)$ & $16(57 \%)$ & 0.54 \\
\hline
\end{tabular}

LY-30, lysis 30 min after MA; MA, maximum amplitude; TEG, thrombelastography. few differences were found between pregnant females, nonpregnant females, and males in demographics and outcomes (online supplemental tables 4-6).

\section{DISCUSSION}

This single-center, retrospective study revealed that injured pregnant females had a more hypercoagulable profile than nonpregnant females and males based on their admission rTEG values-higher $\alpha$ angles and MA values. Pregnant females also had lower LY-30 on admission rTEG. Despite these laboratory derangements, pregnant patients suffered no clinically apparent DVT or PE, contrary to the hypothesis. This finding raises the question of whether sex-related hypercoagulable profiles are harmful, as was found in prior studies linking hypercoagulable profiles to thromboembolic events. ${ }^{19-21}$ Given the lack of associated VTE events, the range of normal TEG values may need to be redefined in subgroups such as pregnant females. In fact, in pregnant females, this hypercoagulable profile (generated from injured males and non-pregnant females) may be protective during pregnancy. When this hypercoagulable profile was absent at admission, there was a high rate of obstetric complications, including a notable rate of fetal demise before gestational viability. Furthermore, a hypocoagulable $\alpha$ angle (low fibrinogen or fibrinogen dysfunction) on arrival rTEG was associated with increased pregnancy complications.

Hypercoagulable TEG profiles seen in pregnant females and non-pregnant females in the present study are consistent with sex-based differences observed in healthy volunteers. ${ }^{1011}$ Francis et al ${ }^{10}$ first demonstrated that healthy non-pregnant females had shorter reaction ( $r$ ) times, indicating the time to the start of clot formation, and higher MA values, when compared with males. Gorton $e t$ al revealed that these sex-based differences in r-time and MA values were further augmented in healthy pregnant females when compared with non-pregnant females. ${ }^{11}$

The initial hypercoagulable TEG profile in pregnant and nonpregnant females observed in the present study parallels previous findings in the trauma population. Schreiber et al observed females had lower $r$-times than males in the first 24 hours after injury. ${ }^{16}$ Pommerening et al observed females had higher $\alpha$ angles and MA values than males in the first 24 hours after injury. ${ }^{17}$ However, they also noted males had a more significant rebound in their coagulation profile after 24 hours, quickly becoming more hypercoagulable than females. Subsequently, males in this multicenter study had higher VTE rates than females. Coleman et al also observed when treating sex as an experimental value that females had a more hypercoagulable profile, less clot formation prolongation, higher MA and angle and lower LY-30 than male counterparts. They also observed that no females died from hemorrhage associated with hyperfibrinolysis, unlike their male counterparts. ${ }^{18}$

The present study supports the premise that estrogen contributes to a hypercoagulable profile seen in pregnant and non-pregnant females, who demonstrated elevated MA values. The MA TEG value represents the strength of the clot and is driven primarily by platelet function. The presence of estrogen and androgen receptors and hormone-responsive enzymes reveal a sex hormone effect on platelets. ${ }^{28-30}$ Coleman et al showed that female platelets have increased aggregation and activation potential. Additionally, estradiol pretreatment feminizes male platelets. ${ }^{31}$ These hormonal effects may play a role in the performance of platelets in trauma-induced coagulopathy and may contribute to sex-specific outcomes in severe trauma. 
Hypercoagulable profiles on arrival after trauma have been associated with an increased risk of VTE events. Brill et $a l^{21}$ performed a prospective study, which found that trauma patients who present with a hypercoagulable TEG had twice the rate of DVTs. Gary et al ${ }^{20}$ retrospectively reviewed patients with extremity trauma and hypercoagulable TEGs (MA $\geq 65$ ); this patient population had a threefold increase risk for VTE events. Additionally, a recent meta-analysis from Harahsheh and Ho revealed that, in multiple clinical settings, hypercoagulability on TEG is associated with a 3.6 times higher odds of VTE development. ${ }^{32}$ In their study, sex was not evaluated in a subgroup analysis. Each of the aforementioned studies advocated for additional VTE prophylaxis for patients who arrive with a hypercoagulable TEG. Importantly, many prior works evaluating the relationship between abnormal rTEG on arrival and VTE development excluded pregnant females from their studies, highlighting the knowledge gap in this important patient population. ${ }^{17}{ }^{18}$ As expected, the present study revealed that pregnant females presented with a more hypercoagulable TEG compared with non-pregnant females and males; however, it was not expected that pregnant patients suffered fewer VTE events. Elevations in estrogen have been linked to a hypercoagulable TEG profile and to increased rates of VTEs in uninjured individuals. This has been observed primarily in those who take hormonal contraception or hormone replacement therapy. ${ }^{33}$ In the setting of trauma, the balance between hemostasis and thrombosis may be further altered in both pregnant and nonpregnant females, resulting in lower overall mortality and, in the case of pregnancy, a lower incidence of VTE. Given that this may be a protective phenotype, this patient population may not benefit from more aggressive VTE prophylaxis, as suggested by the findings in prior studies.

Sharma et al and Della Rocca et al previously noted that pregnant females, especially those in later terms of pregnancy, had higher $\alpha$ angle and MA and lower fibrinolysis by TEG values..$^{15} 34$ The current study found that low k-time, low $\alpha$ angle, and elevated fibrinolysis at admission were associated with increased mortality and pregnancy-related complications. These findings are not surprising given the contribution of fibrinogen concentration and fibrinogen function to these values, as well as the significance of each in maintaining pregnancy to term and without bleeding complications. Fibrinogen is essential to placental development and integrity during pregnancy and poor pregnancy-related outcomes are frequent in patients with hypofibrinogenemia and fibrinogen dysfunction. ${ }^{35}$ As such, what is hypercoagulable in the acutely injured males or non-pregnant females may be protective (by design) for the pregnant female patient and her fetus after injury.

There are limitations to our study. First, our study was a singlecenter retrospective review with a low sample size. This was primarily due to our unique patient population of interest-pregnant women involved in trauma. There were very few patients who met the inclusion criteria of our study, resulting in a small sample size. The present study may be underpowered to detect the infrequent complication of interest: DVT and PE. In addition, the true incidence of DVT and PE in our patient population is unknown, as no duplex surveillance imaging was performed. Therefore, our study should be considered hypothesis generating and should be confirmed with a larger sample size. Second, this patient population has been historically excluded from prospective studies and therefore serial blood samples are not available for assessment of time-related TEG changes after injury. Third, accurate data on pharmacologic contraception or menstruation status were not available and therefore were not accounted for.
Finally, the patients in the present study presented with relatively low ISS and minimal transfusion requirements, which may make the findings difficult to extrapolate to trauma patients presenting in extremis.

\section{CONCLUSION}

Injured pregnant females frequently presented with a profile that would be considered hypercoagulable under reference ranges for non-pregnant trauma patients. However, given the absence of VTE events, this profile may be non-pathologic in pregnant females. In fact, such a profile appears to be protective for carrying the fetus to term and maternal survival.

Contributors LJT and GEH designed the study, and performed the literature search, data collection and analysis. All authors contributed to the data interpretation, article preparation, and critical review of the article.

Funding CEW receives funding from the William Stamps Farish Fund, the Howell Family Foundation, the James H 'Red' Duke Professorship. GEH is supported by the National Institute of General Medical Sciences of the National Institutes of Health (5T32GM008792)

Competing interests None declared.

Patient consent for publication Not required.

Ethics approval The study was reviewed and approved by the McGovern Medical School at UTHealth Committee for the Protection of Human Subjects (study ID: HSCGEN-13-0325).

Provenance and peer review Commissioned; externally peer reviewed.

Data availability statement Data are available upon request.

Open access This is an open access article distributed in accordance with the Creative Commons Attribution Non Commercial (CC BY-NC 4.0) license, which permits others to distribute, remix, adapt, build upon this work non-commercially, and license their derivative works on different terms, provided the original work is properly cited, appropriate credit is given, any changes made indicated, and the use is non-commercial. See: http://creativecommons.org/licenses/by-nc/4.0/.

\section{REFERENCES}

1 Croce MA, Fabian TC, Malhotra AK, Bee TK, Miller PR. Does gender difference influence outcome? J Trauma 2002;53:889-94.

2 Haider AH, Crompton JG, Oyetunji T, Stevens KA, Efron DT, Kieninger AN, Chang DC, Cornwell EE, Haut ER. Females have fewer complications and lower mortality following trauma than similarly injured males: a risk adjusted analysis of adults in the National trauma data bank. Surgery 2009;146:308-15.

3 Napolitano LM, Greco ME, Rodriguez A, Kufera JA, West RS, Scalea TM. Gender differences in adverse outcomes after blunt trauma. J Trauma 2001;50:274-80.

4 Deitch EA, Livingston DH, Lavery RF, Monaghan SF, Bongu A, Machiedo GW. Hormonally active women tolerate shock-trauma better than do men: a prospective study of over 4000 trauma patients. Ann Surg 2007;246:447-53.

5 Magnotti LJ, Fischer PE, Zarzaur BL, Fabian TC, Croce MA. Impact of gender on outcomes after blunt injury: a definitive analysis of more than 36,000 trauma patients. J Am Coll Surg 2008;206:984-91.

6 Lopez M-C, Efron PA, Ozrazgat-Baslanti T, Zhang J, Cuschieri J, Maier RV, Minei JP, Baker HV, Moore FA, Moldawer LL, et al. Sex-based differences in the genomic response, innate immunity, organ dysfunction, and clinical outcomes after severe blunt traumatic injury and hemorrhagic shock. J Trauma Acute Care Surg 2016;81:478-85

7 Haider AH, Crompton JG, Chang DC, Efron DT, Haut ER, Handly N, Cornwell EE. Evidence of hormonal basis for improved survival among females with traumaassociated shock: an analysis of the National trauma data bank. J Trauma 2010;69:537-40

8 Mostafa G, Huynh T, Sing RF, Miles WS, Norton HJ, Thomason MH. Gender-Related outcomes in trauma. J Trauma 2002:53:430-5.

9 Trentzsch H, Lefering R, Nienaber U, Kraft R, Faist E, Piltz S. The role of biological sex in severely traumatized patients on outcomes: a matched-pair analysis. Ann Surg 2015;261:774-80.

10 Francis JL, Francis DA, Gunathilagan GJ. Assessment of hypercoagulability in patients with cancer using the sonoclot analyzer ${ }^{\mathrm{TM}}$ and thromboelastography. Thromb Res 1994.

11 Gorton HJ, Warren ER, Simpson NA, Lyons GR, Columb MO. Thromboelastography identifies sex-related differences in coagulation. Anesth Analg 2000;91:1279-81. 
12 Scarpelini S, Rhind SG, Nascimento B, Tien H, Shek PN, Peng HT, Huang H, Pinto R, Speers $\mathrm{V}$, Reis $\mathrm{M}$, et al. Normal range values for thromboelastography in healthy adult volunteers. Braz J Med Biol Res 2009;42:1210-7.

13 Roeloffzen WW, Kluin-Nelemans HC, Mulder AB, Veeger NJ, Bosman L, de Wolf JT. In normal controls, both age and gender affect coagulability as measured by thrombelastography. Anesth Analg 2010;110:987-94.

14 Kaufmann CR, Dwyer KM, Crews JD, Dols SJ, Trask AL. Usefulness of thrombelastography in assessment of trauma patient coagulation. J Trauma 1997;42:716-22.

15 Sharma SK, Philip J, Wiley J. Thromboelastographic changes in healthy parturients and postpartum women. Anesth Analg 1997;85:94-8.

16 Schreiber MA, Differding J, Thorborg P, Mayberry JC, Mullins RJ. Hypercoagulability is most prevalent early after injury and in female patients. J Trauma 2005;58:475-81.

17 Pommerening MJ, Schwartz DA, Cohen MJ, et al. Hypercoagulability after injury in premenopausal females: A prospective, multicenter study. United States: Surgery, 2014:156. 439-47.

18 Coleman JR, Moore EE, Samuels JM, Cohen MJ, Sauaia A, Sumislawski JJ, Ghasabyan A, Chandler JG, Banerjee A, Silliman CC, et al. Trauma resuscitation consideration: sex matters. J Am Coll Surg 2019:228:760-8.

19 Cotton BA, Minei KM, Radwan ZA, Matijevic N, Pivalizza E, Podbielski J, Wade CE, Kozar RA, Holcomb JB. Admission rapid thrombelastography predicts development of pulmonary embolism in trauma patients. J Trauma Acute Care Surg 2012;72:1470-7.

20 Gary JL, Schneider PS, Galpin M, Radwan Z, Munz JW, Achor TS, Prasarn ML, Cotton BA. Can thrombelastography predict venous thromboembolic events in patients with severe extremity trauma? J Orthop Trauma 2016;30:294-8.

21 Brill JB, Badiee J, Zander AL, Wallace JD, Lewis PR, Sise MJ, Bansal V, Shackford SR. The rate of deep vein thrombosis doubles in trauma patients with hypercoagulable thromboelastography. J Trauma Acute Care Surg 2017;83:413-9.

22 Bagot CN, Leishman E, Onyiaodike CC, Jordan F, Gibson VB, Freeman DJ. Changes in laboratory markers of thrombotic risk early in the first trimester of pregnancy may be linked to an increase in estradiol and progesterone. Thromb Res 2019;178:47-53.

23 Shaydakov ME, Sigmon DF, Bleba J. Thromboelastography. StatPearls: StatPearls Publishing, 2021. https://www.ncbi.nlm.nih.gov/books/NBK537061/.

24 Huzar TF, Martinez E, Love J, George TC, Shah J, Baer L, Cross JM, Wade CE, Cotton BA. Admission rapid thrombelastography ( $r T E G \circledast$ ) values predict resuscitation volumes and patient outcomes after thermal injury. J Burn Care Res 2018;39:345-52.
25 Holcomb JB, Minei KM, Scerbo ML, Radwan ZA, Wade CE, Kozar RA, Gill BS, Albarado R, McNutt MK, Khan S, et al. Admission rapid thrombelastography can replace conventional coagulation tests in the emergency department: experience with 1974 consecutive trauma patients. Ann Surg 2012;256:476-86.

26 Moore HB, Moore EE, Liras IN, et al. Targeting resuscitation to normalization of coagulating status: hyper and hypocoagulability after severe injury are both associated with increased mortality. Am I Surg. Published online 2017.

27 Chapman MP, Moore EE, Ramos CR, Ghasabyan A, Harr JN, Chin TL, Stringham JR, Sauaia A, Silliman CC, Banerjee A. Fibrinolysis greater than 3\% is the critical value for initiation of antifibrinolytic therapy. J Trauma Acute Care Surg 2013;75:961-7.

28 Faraday N, Goldschmidt-Clermont PJ, Bray PF. Gender differences in platelet GPIIb-IIla activation. Thromb Haemost 1997;77:748-54.

29 Khetawat G, Faraday N, Nealen ML, Vijayan KV, Bolton E, Noga SJ, Bray PF. Human megakaryocytes and platelets contain the estrogen receptor beta and androgen receptor (AR): testosterone regulates Ar expression. Blood 2000;95:2289-96.

30 Chen LY, Mehta JL. Further evidence of the presence of constitutive and inducible nitric oxide synthase isoforms in human platelets. J Cardiovasc Pharmacol 1996;27:154-8.

31 Coleman JR, Moore EE, Kelher MR, Samuels JM, Cohen MJ, Sauaia A, Banerjee A, Silliman CC, Peltz ED. Female platelets have distinct functional activity compared with male platelets: implications in transfusion practice and treatment of trauma-induced coagulopathy. J Trauma Acute Care Surg 2019;87:1052-60.

32 Harahsheh Y, Ho KM. Use of viscoelastic tests to predict clinical thromboembolic events: a systematic review and meta-analysis. Eur J Haematol 2018;100:113-23.

33 Abou-Ismail MY, Citla Sridhar D, Nayak L. Estrogen and thrombosis: a bench to bedside review. Thromb Res 2020.

34 Della Rocca G, Dogareschi T, Cecconet T, Buttera S, Spasiano A, Nadbath P, Angelini M, Galluzzo C, Marchesoni D. Coagulation assessment in normal pregnancy: thrombelastography with citrated non activated samples. Minerva Anestesiol 2012;78:1357-64.

35 Miesbach W, Galanakis D, Scharrer I. Treatment of patients with dysfibrinogenemia and a history of abortions during pregnancy. Blood Coagul Fibrinolysis 2009;20:366-70. 